\title{
Correction to: Children's dental anxiety (self and proxy reported) and its association with dental behaviour in a postgraduate dental hospital
}

\author{
S. AIGharebi ${ }^{1}$ M. Al-Halabi ${ }^{1}$ M. Kowash ${ }^{1} \cdot$ A. H. Khamis ${ }^{2} \cdot$ I. Hussein $^{1}$
}

Published online: 9 May 2020

(c) European Academy of Paediatric Dentistry 2020

\section{Correction to: European Archives of Paediatric Dentistry https://doi.org/10.1007/s40368-020-00517-x}

In the original publication of the article the third author's name "M. Kowash" was submitted as "K. Mawlood" which was left unnoticed in the later stages. The correct name is as published in this erratum and the original article has been corrected.

Publisher's Note Springer Nature remains neutral with regard to jurisdictional claims in published maps and institutional affiliations.

The original article can be found online at https://doi.org/10.1007/ s40368-020-00517-x.

I. Hussein

iyad.hussein@mbru.ac.ae

1 Paediatric Dentistry, Hamdan Bin Mohammed College of Dental Medicine, Mohammed Bin Rashid University of Medicine and Health Sciences, Dubai, UAE

2 Biostatistics, Hamdan Bin Mohammed College of Dental Medicine, Mohammed Bin Rashid University of Medicine and Health Sciences, Dubai, UAE 